\title{
Drosophila Serpin 4 Functions as a Neuroserpin-Like Inhibitor of Subtilisin-Like Proprotein Convertases
}

\author{
Thomas Osterwalder, Angela Kuhnen, William M. Leiserson, You-Seung Kim, and Haig Keshishian \\ Department of Molecular, Cellular, and Developmental Biology, Yale University, New Haven, Connecticut 06520-8103
}

\begin{abstract}
The proteolytic processing of neuropeptide precursors is believed to be regulated by serine proteinase inhibitors, or serpins. Here we describe the molecular cloning and functional expression of a novel member of the serpin family, Serine protease inhibitor 4 (Spn4), that we propose is involved in the regulation of peptide maturation in Drosophila. The Spn4 gene encodes at least two different serpin proteins, generated by alternate splicing of the last coding exon. The closest vertebrate homolog to Spn4 is neuroserpin. Like neuroserpin, one of the Spn4 proteins (Spn4.1) features a unique C-terminal extension, reminiscent of an endoplasmic reticulum (ER) retention signal; however, Spn4.1 and neuroserpin have divergent reactive site loops, with Spn4.1 showing a generic recognition site for furin/SPC1, the founding member of the intracellularly active family of subtilisin-like proprotein convertases (SPCs). In vitro, Spn4.1 forms SDS-stable complexes with the SPC furin and directly inhibits it. When Spn4.1 is overexpressed in specific peptidergic cells of Drosophila larvae, the animals exhibit a phenotype consistent with disrupted neuropeptide processing. This observation, together with the unique combination of an ER-retention signal, a target sequence for SPCs in the reactive site loop, and the in vitro inhibitory activity against furin, strongly suggests that Spn4.1 is an intracellular regulator of SPCs.
\end{abstract}

Key words: neuroserpin; proprotein convertase; Drosophila; neuropeptide; ecdysis; neurosecretion; serine protease

\section{Introduction}

The maturation of many secreted proteins, membrane-bound receptors, and bioactive peptides depends on the regulated proteolytic cleavage of proproteins. Proteolysis is often catalyzed by subtilisin-like proprotein convertases (SPCs), which are $\mathrm{Ca}^{2+}$ dependent serine proteases (for review, see Barr, 1991; Steiner, 1998; Thacker and Rose, 2000). Although SPCs are structurally diverse, they all cleave their proprotein substrates at specific points along the secretory pathway. The proteases target a tandem array of basic amino acids, usually arginine or lysine residues with the sequence $\mathrm{R} / \mathrm{K}-\mathrm{R} / \mathrm{K}$ or $\mathrm{R} / \mathrm{K}-\mathrm{X}-\mathrm{X}-\mathrm{R} / \mathrm{K}$ (Seidah and Chretien, 1999).

The processing serine proteases are often regulated by specific inhibitors known as serpins (Hook et al., 1994). Serpins comprise a large superfamily of structurally related proteins that interact with their target proteases as "suicide substrates" (Huntington and Carrell, 2001). Serpins form covalent acyl-enzyme intermediates that distort the bound protease and render it inactive. Covalent serpinprotease complexes withstand denaturing conditions, like boiling SDS, and can be analyzed by SDS-PAGE. Although the serpins were

Received June 25, 2003; revised April 20, 2004; accepted April 22, 2004.

This work was supported by a junior researcher fellowship from the Swiss National Science Foundation to T.0. and by grants from the National Institutes of Health and the National Science Foundation to H.K. We thank Dr. Paul Taghert for providing the c929-Gal4 driver line (originally generated by Dr. Kim Kaiser, University of Glasgow) and Dr. Yoonseong Park and Dr. Michael Adams for kindly providing the transgenic line 2E3G. The mAb 3C10 was obtained from the Developmental Studies Hybridoma Bank (University of lowa). We thank Drs. Craig Crews and Kenneth Nelson for access to equipment, members of the Keshishian lab for comments on this manuscript, and Dr. Carl Hashimoto for informative discussions and the sharing of prepublication data.

Correspondence should be addressed to Haig Keshishian, Department of Molecular, Cellular, and Developmental Biology, Yale University, P.0. Box 208103, New Haven, CT 06520-8103.E-mail: haig.keshishian@yale.edu.

T. Osterwalder's present address: EMPA St. Gallan, MaTisMed, Lerchenfeldstrasse 5, CH-9014 St. Gallen, Switzerland.

DOI:10.1523/JNEUROSCI.5577-03.2004

Copyright $\odot 2004$ Society for Neuroscience $\quad$ 0270-6474/04/245482-10\$15.00/0 initially characterized as inhibitors of chymotrypsin-like extracellular serine proteases, in principle they can inhibit any protease that forms a covalent intermediate with the substrate. Examples of serpin-mediated regulation of intracellular processing events include the inhibition of the serine and thiol proteases of neuroendocrine cells (Hwang et al., 1999,2002; Fell et al., 2002), as well as the inhibition of SPCs (Dahlen et al., 1998; Dufour et al., 1998; Jean et al., 1998; Tsuji et al., 1999).

In this paper we provide evidence that Drosophila serpin 4 (Spn4), a protein expressed in both the CNS and the periphery, acts as a physiological inhibitor of SPCs, and we propose a role for Spn4 in regulating peptide processing. Spn4 was initially identified as one of six serpins expressed in Drosophila oocytes (Han et al., 2000) and is the closest Drosophila homolog to neuroserpin, a vertebrate neuronal serpin (Osterwalder et al., 1996; Krueger et al., 1997; Schrimpf et al., 1997). We analyzed the Spn4 gene and describe two of its alternative splice isoforms, referred to as Spn4.1 and Spn4.2. The Spn4.1 protein can form in vitro covalent complexes with several serine proteases and binds to and biochemically inhibits the SPC furin. We also overexpressed Spn4.1 in vivo in various peptidergic cells, reasoning that the phenotype of an overexpressed serpin might mimic the loss of function (LOF) phenotype of the cognate proteases. The overexpression of either Spn4.1 or vertebrate neuroserpin resulted in molting abnormalities that resemble the hypomorphic phenotype of the serine protease gene amontillado, the Drosophila homolog of SPC2 (Siekhaus and Fuller, 1999; Rayburn et al., 2003), as well as the LOF phenotype of the gene encoding ecdysis triggering hormone (ETH) (Park et al., 1999, 2002). Because in vitro complex formation experiments and biochemical studies confirmed the ability of Spn4.1 to interact with recombinant furin, we propose here that the Drosophila Spn4 and potentially its mammalian 
homolog, neuroserpin, are involved in the cellular regulation of prohormone convertases.

\section{Materials and Methods}

Fly stocks, crosses, and analysis of viability. All Drosophila strains were maintained in a $y w$ or $w^{1118}$ background. Gal4 driver lines included the following: 24B-Gal4, (P\{GawB $\}$ how $^{24 B}$ ) (Brand and Perrimon, 1993), which drives expression in muscles and other mesodermally derived tissues, nerves, and trachea, as well as a subset of cells in the CNS (see also Discussion), and c929-Gal4 with the second chromosome insert $\mathrm{P}\{\mathrm{GawB}\} \mathrm{Crc}^{929}$, which was generated in the laboratory of Dr. Kim Kaiser (University of Glasgow) and drives expression in $\sim 200$ (peptidergic) CNS neurons as well as in the peritracheal Inka cells (O'Brien and Taghert, 1998). The generation of the Upstream Activating Sequence (UAS) lines Spn4.1, UAS-Spn4.2, UAS-Spn27A, and UAS-neuroserpin (UAS-Neus) are described below. The UAS-2xEGFP line, which carries a dicistronic construct of enhanced green fluorescent protein (EGFP) cDNAs (Halfon et al., 2002), served as a control line.

All of the crosses and egg lays were done at $25^{\circ} \mathrm{C}$ and $60-80 \%$ relative humidity. For all crosses, males and virgin females were mated for several days in vials containing cornmeal-molasses food before they were transferred to apple juice plates with fresh, live yeast for egg lays. In all cases, parents were homozygous for either the UAS reporter or the Gal4 driver, so that all progeny received a single UAS and a single Gal4 chromosome.

To monitor embryonic survival, we examined egg lay plates $24-36 \mathrm{hr}$ after egg laying and compared the number of empty eggshells (indicating viable first instar larvae) with the number of eggs initially laid, calculated as $n$ (eggshells) $/ n$ (unhatched eggs + eggshells) $\times 100 \%$. For first to second instar molting, first instar larvae were transferred to fresh apple juice plates with live yeast, and the number of second instar larvae (using the mouth hooks to stage them) was counted $24-36 \mathrm{hr}$ after the transfer. The molting rate was calculated as $n$ (second instar) $/ n$ (first + second instar) $\times 100 \%$. Finally, adult survival was calculated as $n$ (adults) $/ n$ (pupae + pupal cases $) \times 100 \%$, in which pupae and eclosed adult animals were counted after the crosses had been conducted in fly vials.

Chromosomal in situ hybridization. Salivary glands were dissected from crawling third instar larvae and squashed as described (http://www.fruitfly. org/about/methods/cytogenetics.html). An Spn4-specific biotinylated DNA probe was generated using a Biotin-High Prime kit (Boehringer Mannheim, Indianapolis, IN) according to the manufacturer's recommendations, with a $3.5 \mathrm{~kb}$ genomic EcoRI fragment (location 0.3-3.8 in Fig. $1 B$ ) spanning the entire coding region of the $S p n 4$ gene as a template. After hybridization of the probe to fixed polytene chromosomes, the chromosomes were washed, incubated with Vectastain avidin-biotinylated peroxidase complex (Vector Laboratories, Burlingame, CA), and the location of the Spn4 probe was visualized by a diaminobenzidine hydrogen peroxide reaction. Chromosomes were counterstained with Giemsa, and the cytological location of Spn 4 was determined by comparison with reference chromosomes (Sorsa, 1988).

Generation of UAS-serpin transformants. All Drosophila expressed sequence tag (EST) clones were obtained from Research Genetics through Invitrogen (Carlsbad, CA). To generate the P-element-based transformation vectors $\mathrm{pP}\{\mathrm{UAS}-\mathrm{Spn} 4.1\}$ and $\mathrm{pP}\{\mathrm{UAS}-\mathrm{Spn} 4.2\}$, a $2.2 \mathrm{~kb}$ EcoRI$K p n I$ fragment of the EST clone LD12792 was subcloned into pUAST (Brand and Perrimon, 1993) to generate pP\{UAS-Spn4.1 $\Delta$ sig\}. A $1.1 \mathrm{~kb}$ EcoRI-NotI fragment of the EST clone GH08104 was then used to replace the presumably truncated $5^{\prime}$ portion of the Spn 4.1 transcript to generate $\mathrm{pP}\{\mathrm{UAS}-\mathrm{Spn} 4.1\}$. To generate $\mathrm{pP}\{\mathrm{UAS}-\mathrm{Spn} 4.2\}$, the entire ORF and portions of the untranslated regions in $\mathrm{pP}\{\mathrm{UAS}-\mathrm{Spn} 4.1 \Delta \mathrm{sig}\}$ were replaced by a $1.4 \mathrm{~kb}$ fragment of GH08104. For pP\{UAS-Neus\}, a $1.6 \mathrm{~kb}$ NotI$X$ hoI fragment of the chicken neuroserpin cDNA sc13al (Osterwalder et al., 1996) was cloned into pUAST, and for $\mathrm{pP}\{\mathrm{UAS}-\mathrm{Spn} 27 \mathrm{~A}\}$, a 1.6kb XhoI$\mathrm{XbaI}$ fragment of CK0349 was subcloned into pUAST. DNA for microinjection was prepared by Qiagen maxi-prep column (Qiagen, Valencia, CA), and UAS-serpin transformation vectors and the helper plasmid $\mathrm{p} \pi$ $25.7 \mathrm{wc} \Delta 2-3$ were coinjected into $w^{1118}$ embryos in a ratio of 5:1 (Rubin and Spradling, 1982). In all cases, two or more independent homozygous-viable P-element insertions on the second and third chromosome (four or more total lines) were obtained and analyzed in trans to the respective Gal4 drivers.
Generation and purification of recombinant Spn4.1- $H_{6}$. Using the PCR primers DNSEX1F (5'-GTCCATATGGCTGACGCCGCCCACC-3'; unique NdeI restriction site underlined) and DNSEX2B (5' -ATCAGGTACCATCAAAGCTTATCATGC-3'; unique HindIII restriction site underlined), the entire ORF of Spn 4.1 minus the $\mathrm{N}$-terminal 32 amino acids (thus less the presumptive signal sequence for secretion) was amplified from the EST clone LD12792. This was ligated into the NdeI-HindIII cut expression Vector pET21a (Invitrogen) in frame with the C-terminal linker and the 6xHis tag to generate the transformation vector pET21: Spn4.1- $\mathrm{H}_{6}$ and verified by sequencing (Keck Foundation Biotechnology Resource Laboratory at Yale University, New Haven, CT). Production of recombinant Spn4.1- $\mathrm{H}_{6}$ was induced in the Escherichia coli expression host strain BL21(DE3) with $0.5 \mathrm{~mm}$ Isopropyl-beta-D-thiogalactopyranoside for $6 \mathrm{hr}$ at $30^{\circ} \mathrm{C}$, after which bacteria were harvested and lysed by lysozyme treatment and repeated sonification. $\mathrm{Spn} 4.1-\mathrm{H}_{6}$ was purified from the crude lysate by $\mathrm{Ni}^{2+}$-NTA affinity chromatography (Qiagen, Valencia, $\mathrm{CA})$. The most concentrated fractions contained $>90 \%$ full-length Spn4.1- $\mathrm{H}_{6}$ (judged by SDS-PAGE and Coomassie stain) and were dialyzed against $50 \mathrm{~mm} \mathrm{NaHCO}_{3}, 100 \mathrm{~mm} \mathrm{NaCl}$ and stored at $4^{\circ} \mathrm{C}$ for further use. Protein concentration was determined by absorption spectroscopy at $280 \mathrm{~nm}$.

Antisera production and affinity purification. Guinea pig antiserum was generated using $\mathrm{Spn} 4.1-\mathrm{H}_{6}$ that had been purified by preparative SDSPAGE and applied intramuscularly (Cocalico Biologicals, Reamstown, PA). The antiserum obtained after four or more boosts (guinea pig antiSpn4.1- $\mathrm{H}_{6}$ ) was used without further purification.

Antisera against peptides from the "core" region of Spn4 (KHLTRPDTFHLDGERT) or against the C terminus of Spn4.1 (VRLEENTFASSEHDEL) were raised in rabbits (Alpha Diagnostic International, San Antonio, TX). The peptides were linked via an N-terminal Cys to KLH and applied in several boosts intramuscularly. The antisera obtained after four boosts (anti-core peptide $\mathrm{B}$ and anti-C-terminal peptide $\mathrm{C}$, respectively) were further purified by affinity chromatography using $\mathrm{Spn} 4.1-\mathrm{H}_{6}$ coupled to Sepharose 4B (Amersham Biosciences, Piscataway, NJ). To demonstrate specificity of signals for Spn $4.1-\mathrm{H}_{6}$ or the antigenic peptides, respectively, preincubation experiments were performed (see Fig. $2 B$ ). In those cases, concentrated antisera were preincubated for several hours with either $1 \mathrm{mg} / \mathrm{ml} \mathrm{Spn} 4.1-\mathrm{H}_{6}$ or the specific peptides, respectively, before they were diluted to working concentrations. We note that the sequence used to generate the core-specific antiserum is common to all Spn4 isoforms. This antiserum could conceivably recognize all Spn4 isoforms. Similarly, the antiserum generated to Spn4.1- $\mathrm{H}_{6}$ could also recognize all isoforms.

Immunocytochemistry and tissue in situ hybridization. Immunocytochemical detection of Spn 4 in the larval brain was as described previously (Keshishian et al., 1993). Briefly, crawling third instar larvae from the Canton $S$ or the $w^{1118}$ line were filleted and fixed with $4 \%$ paraformaldehyde for 30-45 min at room temperature (RT). Nonspecific binding was blocked by $1 \mathrm{hr}$ incubation with $1 \%$ bovine serum albumin and $0.5 \%$ Triton X-100 in PBS. Incubations with primary and secondary antibodies were performed in blocking buffer for $2 \mathrm{hr}$ at RT or for $16 \mathrm{hr}$ at $4^{\circ} \mathrm{C}$. Primary antibodies were used at $1-5 \mu \mathrm{g} / \mathrm{ml}$ (rabbit anti-core peptide and rabbit anti-C-terminal peptide) or at a dilution of 1:5000 (guinea pig anti-Spn4.1- $\mathrm{H}_{6}$; see below for preparation of Spn4 antibodies). The antiEven skipped monoclonal antibody $(\mathrm{mAb}) 3 \mathrm{C} 10$ was used at a dilution of 1:10. Fluorescently labeled secondary antibodies Alexa Fluor488 antirabbit, Alexa Fluor568 anti-guinea pig, or Alexa Fluor568 anti-mouse were from Molecular Probes (Eugene, OR) and were used at a dilution of 1:500. The transgenic fly line 2E3G, which expresses an ecdysis triggering hormone (ETH)-GFP fusion protein (Park et al., 2002) was used for double labeling of Spn4 and epitracheal cells. A Bio-Rad MRC 1024 confocal microscope with LaserSharp 3.0 imaging software (Bio-Rad Laboratories, Hercules, CA) was used to image fluorescently labeled antibodies and GFP.

Tissue in situ hybridization of Spn 4 mRNA in larval brains was modified from the embryo method described by Tautz and Pfeifle (1989). Briefly, larval brains or larval filets were fixed for 30-45 min at RT with $4 \%$ paraformaldehyde, extensively washed in PBS at $4^{\circ} \mathrm{C}$, incubated for $20 \mathrm{~min}$ in $0.2 \mathrm{~N} \mathrm{HCl}$ and for $10 \mathrm{~min}$ in $20 \mathrm{mg} / \mathrm{ml}$ Proteinase $\mathrm{K}$, with washes in PBS with $0.1 \%$ Tween 20 (PBTween) in between, and fixed 
again for $15 \mathrm{~min}$ at RT with $4 \%$ paraformaldehyde. After acetylation (acetylation buffer: $150 \mu \mathrm{l}$ of $5 \mathrm{M} \mathrm{NaCl}, 75 \mu \mathrm{l}$ of triethanolamine, $40 \mu \mathrm{l}$ of $\mathrm{HCl}, 4.7 \mathrm{ml}$ of $\mathrm{dH}_{2} \mathrm{O}, 12 \mu \mathrm{l}$ of acetic anhydride) for $10 \mathrm{~min}$ at RT, the tissue was first prehybridized for $1 \mathrm{hr}$ at $59^{\circ} \mathrm{C}$ in hybridization buffer $(50$ $\mathrm{ml}$ of formamide, $25 \mathrm{ml}$ of $20 \times$ SSC, $1 \mathrm{ml}$ of $10 \%$ Tween $20,1 \mathrm{ml}$ of 10 $\mathrm{mg} / \mathrm{ml}$ herring sperm DNA, $18 \mathrm{ml}$ of $\mathrm{dH}_{2} \mathrm{O} ; 50 \mu \mathrm{g} / \mathrm{ml}$ of glycogen added just before use) and then hybridized with Spn4 antisense cRNA [Spn4 cRNA probes were derived from the full-length Spn4.1 cDNA clone LD12792 (see below) using the Boehringer digoxigenin (DIG) RNA labeling mix, and T3 or T7 RNA polymerase according to the manufacturer's recommendations] in hybridization buffer for $24 \mathrm{hr}$ at $59^{\circ} \mathrm{C}$, and finally washed with several changes of hybridization buffer for a total of $16 \mathrm{hr}$ at $60^{\circ} \mathrm{C}$. Spn 4 was visualized with an alkaline phosphatase-conjugated antiDIG antibody (Boehringer Mannheim) according to Boehringer's guidelines (http://www.roche-applied-science.com/fst/products.htm?/ PROD_INF/MANUALS/DIG_MAN/dig_toc.htm).

Complex formation analysis. The serine proteases used were commercially available preparations of trypsin (T1426), chymotrypsin (C7762), elastase (E1250), plasmin (P5380), thrombin (T4648), and a recombinant form of human furin (F2677) from Sigma (St. Louis, MO) and dissolved in $\mathrm{dH}_{2} \mathrm{O}$, where necessary. Ten to $300 \%$ (molar ratio respective to $\mathrm{Spn} 4.1-\mathrm{H}_{6}$ ) of the protease was incubated with $1 \mu \mathrm{g}$ of Spn $4.1-\mathrm{H}_{6}$ in 10 $\mu \mathrm{l}$ of complex formation buffer [ $66 \mathrm{~mm}$ Tris, $133 \mathrm{~mm} \mathrm{NaCl}, 0.1 \%(\mathrm{w} / \mathrm{v})$ PEG-3250, pH 7.5; or 100 mm HEPES, $1 \mathrm{~mm} \mathrm{CaCl}_{2}, 0.5 \%$ Triton X-100, $\mathrm{pH} 7.5$ for reactions with furin] for $15 \mathrm{~min}$ at $22^{\circ} \mathrm{C}$. After the reaction, proteins were immediately denatured by boiling for 3-5 min in SDSPAGE sample buffer (125 mu Tris-Cl, pH 6.8, 30\% glycerol, 4\% SDS, 5\% $\beta$-mercaptoethanol, $0.01 \%$ bromophenol blue), and an equivalent of 200 ng of Spn4.1- $\mathrm{H}_{6}$ was applied to each gel lane (see below).

Furin inhibition assays and general kinetic methods. To determine furin inhibition by Spn4.1, recombinant human furin was mixed with different amounts of Spn4.1- $\mathrm{H}_{6}$ in reaction buffer (100 mM HEPES, $1 \mathrm{~mm}$ $\mathrm{CaCl}_{2}, 0.5 \%$ Triton X-100, pH 7.5) in separate wells of a 96-well plate (triplicates were measured for each Spn4.1- $\mathrm{H}_{6}$ concentration) and incubated for $30 \mathrm{~min}$ at $22^{\circ} \mathrm{C}$. After incubation, the amidolytic reaction in each well was started simultaneously by adding the fluorogenic furin substrate pERTKR-MCA (Bachem; item I-1650), and the amidolytic activity of furin was measured at 20 min intervals in a 96-well spectrofluorometer (PerkinElmer Wallac; model 1420). Inhibition of furin was determined by expressing the furin activity in the inhibited wells as percentage of the uninhibited enzyme activity and plotting the residual activity against the Spn4.1- $\mathrm{H}_{6}$ concentration in the well. Final concentrations of furin, substrate, and Spn $4.1-\mathrm{H}_{6}$ were $2 \mathrm{nM}, 200 \mu \mathrm{M}$, and $0-16 \mathrm{nM}$, respectively.

The kinetics of the interaction between $\mathrm{Spn} 4.1-\mathrm{H}_{6}$ and recombinant human furin was determined by the progress curve method (Morrison and Walsh, 1988). Reactions were started by adding $2 \mathrm{~nm}$ furin to the reaction buffer containing $200 \mu \mathrm{m}$ of pERTKR-MCA and variable inhibitor concentrations (0-64 nм Spn4.1- $\left.\mathrm{H}_{6}\right)$. Because the interaction between serine proteases and serpins is assumed to follow slow binding kinetics, product formation as measured by absorbance $(A)$ was described with Equation 1:

$$
A=v_{\mathrm{s}} t+\left(v_{\mathrm{z}}-v_{\mathrm{s}}\right)\left(1-e^{-\mathrm{k}^{\prime} t}\right) / k^{\prime}+A_{0} .
$$

$v_{s}$ and $v_{z}$ represent the reaction velocities at steady state and zero time, respectively; $k^{\prime}$ represents the apparent first-order rate constant; and $A_{O}$ is a displacement factor for compensation of uncertainties of absorbance at the beginning of the reaction. For each of several inhibitor concentrations, $v_{s}, v_{z}$, $k^{\prime}$, and $A_{0}$ were determined by fitting Equation 1 to the data sampled from progress curves. The association constant was then determined from the relationship shown in Equation 2 (Morrison and Walsh, 1988):

$$
k^{\prime}=k_{\mathrm{d}}+[I] k_{\mathrm{a}} /\left(1+[S] / K_{\mathrm{m}}\right),
$$

in which the $K_{\mathrm{m}}$ of pERTKR-MCA is $23 \mu \mathrm{M}$ for this furin (Jean et al., 1995).

Drosophila protein preparation. For developmental Western blots, Drosophila embryos and larvae were collected after $3 \mathrm{hr}$ egg lays in large culture cages and allowed to develop to the appropriate stage. For the mass isolation of adult heads and bodies, adult flies were frozen in liquid nitrogen, and body parts were separated using a series of steel sieves. Larval brains were manually dissected from crawling third instar larvae. Soluble proteins were extracted from embryos, larvae, adult flies, or body parts, respectively, by homogenization in protein extraction buffer $(100$ mм KCl, 20 mм HEPES, 5\% glycerol, 10 mм EDTA, 0.1\% Triton X-100, $1 \mathrm{~mm}$ dithiothreitol) supplemented with the "complete" protease inhibitor mixture (Boehringer Mannheim, Indianapolis, IN). Protein concentration was determined using a variant of the Lowry method (Bio-Rad Laboratories), and $15 \mu \mathrm{g}$ of total protein was loaded per lane.

SDS-PAGE and Western blot analysis. SDS-PAGE was essentially as described by Laemmli (1970). Separated proteins were electrotransferred to nitrocellulose membranes (Schleicher \& Schuell, Keene, NH) as described by Towbin et al. (1979). Immunodetection of Spn4.1 was performed using GP anti-Spn4.1- $\mathrm{H}_{6}$ (see above) at a dilution of 1:2000, or affinity-purified R anti-core pep, or R anti-C-term pep, respectively, at 1:500. Peroxidase-conjugated anti-guinea pig or anti-rabbit antibodies (Jackson ImmunoResearch Laboratories, West Grove, PA) were used at a dilution of 1:20,000, and the SuperSignal ECL detection kit (Pierce, Rockford, IL) was applied according to the manufacturer's recommendations.

\section{Results}

\section{Molecular analysis of the Spn 4 gene}

Computational analysis of the Drosophila genome has revealed 35 genes that potentially code for serpin proteins (Adams et al., 2000; Rubin et al., 2000). Of these, 19 have reported ESTs. The number of functional serpin proteins in Drosophila is likely $>19$, because invertebrate serpin genes often have multiple exons that code for reactive centers, allowing for mutually exclusive splicing (Jiang et al., 1994; Kruger et al., 2002). Of particular interest is Spn4, which was reported as one of six serpin-like genes expressed in Drosophila oocytes (Han et al., 2000). Spn4 protein shows significant similarity ( $30 \%$ identity on an amino acid level) to the vertebrate neuronal serpin neuroserpin (Osterwalder et al., 1996; Krueger et al., 1997; Schrimpf et al., 1997). Several EST clones from separate libraries indicated expression of Spn4 during all developmental stages and in the adult head. In accordance with the predicted cytological location, we mapped Spn 4 cytologically to region 42D-E on the right arm of the second chromosome (Fig. $1 A$, inset), near the serpin cluster of the necrotic locus at $43 \mathrm{~A}$ (Green et al., 2000). We determined the complete sequence of two cDNA clones associated with the Spn4 gene, LD12792 and GH8104. Furthermore, we identified a single P1-clone spanning the Spn4 gene by hybridization of a P1 array with one of these cDNA clones. We determined the nucleotide sequence of several kilobases of genomic DNA of the corresponding region, which was confirmed by the data obtained from the Drosophila genome sequence project. Analysis of the cDNA and genomic sequences revealed the existence of at least two Spn 4 mRNAs (Fig. $1 A$ ). Although both mRNAs share exons 2 and 3, encoding most of the "barrel" protein core, alternative splicing of exon 4 leads to predicted proteins with different $\mathrm{C}$ termini. Because most of the reactive site loop including the reactive site (P1) is encoded on exon 4 , the different protein products (subsequently called Spn4.1 and Spn4.2, respectively) could have radically different target proteases. Spn4.1 and Spn 4.2 correspond to the Spn 4 transcripts 1 and 5 (coding for the protein variants Spn4A and Spn4D), respectively, according to the nomenclature of a recent analysis of the locus (Kruger et al., 2002). In Figure $1 B$ the primary sequences of the $\mathrm{C}$-terminal portions (including the hinge region, the reactive site, and the region of the serpin signature) of these two Spn4 gene products are aligned to another Drosophila serpin (Spn27A) and to human neuroserpin (hNEUS). Both Spn4.1 and Spn4.2 show a serpin signature near the C terminus (Prosite PS00284) (Henikoff and Henikoff, 1994) as well as an amino acid composition in the hinge region that would support the structural requirements for inhibitory serpins (Hopkins and Stone, 


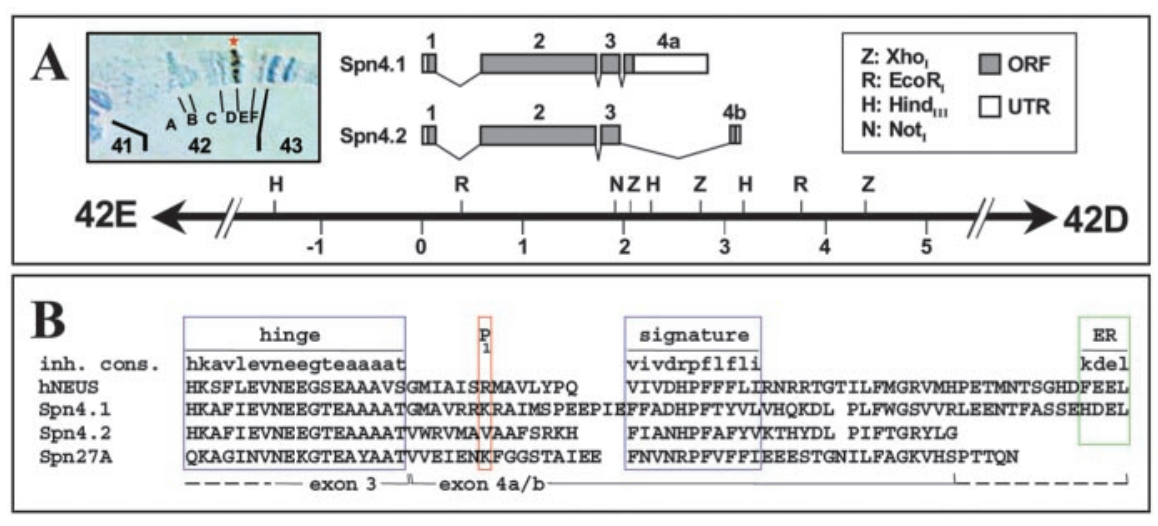

Figure 1. Cytological localization and structure of the Spn4 gene. A, Organization of the Spn4 gene and differentially spliced transcripts. The bold line represents the genomic region spanning the Spn4 gene, whereas marks above indicate consensus recognition sites for restriction enzymes and marks below indicate the distance (in thousands of base pairs) from a cluster of three putative transcription start sites. Two alternatively spliced Spn4 transcripts (Spn4.1 and Spn4.2) are represented above the genomic structure. Inset, In situ hybridization of Spn4-specific probes to polytene chromosome preparations of larval salivary glands localizes Spn4 (star) in the cytological region 42D-E (Sorsa, 1988). B, Alignment of reactive site loops of mammalian neuroserpin (Neus) and the Drosophila serpins Spn4.1, Spn4.2, and Spn27A. The consensus sequence (inh. cons.) for mammalian inhibitory serpins is also shown. The blue frames enclose the reactive site hinge and the serpin signature sequences. The red frame denotes the P1 amino acid, and the green frame denotes the sequence of a generic ER-retention signal (ER).

1995); however, Spn4.1 has a basic amino acid at position P1, suggesting that it targets serine proteases with basic substrate specificity. Interestingly, Spn4.1 and neuroserpin share a similar motif at their C termini: both end with a tetrapeptide reminiscent of an ER retention signal (Pelham, 1990).

\section{Spn4 expression during development}

Using Western blots we assayed the expression of the Spn4 proteins throughout development (Fig. 2A). An antiserum generated against recombinant $\mathrm{Spn} 4.1-\mathrm{H}_{6}$ recognized two major bands at $\sim 40$ and $45 \mathrm{kDa}$. A third band at $\sim 65 \mathrm{kDa}$ was recognized only at late embryogenesis (9-21 hr after egg laying). The $45 \mathrm{kDa}$ band probably corresponds to the uncleaved Spn 4.1 protein, whereas the $40 \mathrm{kDa}$ band might represent cleaved Spn4.1 protein, or one of the shorter isoforms as described by Kruger et al. (2002). The identity of the $65 \mathrm{kDa}$ band is not known. The 40 $\mathrm{kDa}$ isoform was present throughout development, whereas the $45 \mathrm{kDa}$ form was dynamically expressed with a peak at 9-12 hr of embryonic development and was almost undetectable in larval total protein extracts (Fig. 2A, Embryo and Larva). The $45 \mathrm{kDa}$ Spn 4 protein was also observed in CNS extracts from crawling third instar larvae (labeled L $3_{\mathrm{CNS}}$ ), whereas only the $40 \mathrm{kDa}$ form could be detected in protein extracts from extracts from the posterior two-thirds of the larvae (labeled L $3_{\text {BODY }}$ ). In adults the 45 $\mathrm{kDa}$ protein was the most abundant Spn 4 isoform in head tissue (labeled $\mathrm{A}_{\mathrm{HEAD}}$ ), whereas the $40 \mathrm{kDa}$ form predominated in protein extracts from the thorax and abdomen (labeled $A_{B O D Y}$ ).

Figure $2 \mathrm{~B}$ shows that both the 40 and the $45 \mathrm{kDa}$ bands are specific for the Spn4 protein, as demonstrated by preabsorbtion of the antiserum with recombinant protein (left panel, lane R). Furthermore, two independently raised and affinity-purified antisera against different peptide sequences from the Spn4.1 protein (see Materials and Methods) recognize in a peptide-specific manner the $45 \mathrm{kDa}$ protein from larval CNS extracts (Fig. $2 \mathrm{~B}$, middle panel, Core Peptide B, and right panel, C-term. Peptide C). Preabsorbtion of the antisera with the peptides against which they were raised abolished the $45 \mathrm{kDa}$ band (Fig. $2 \mathrm{~B}$, middle panel, lane $\mathrm{B}$, and right panel, lane $\mathrm{C}$ ). The $45 \mathrm{kDa}$ band was also abolished by preincubation with recombinant Spn4.1- $\mathrm{H}_{6}$ (lanes R).
This band (labeled Spn4.1 and marked with a star) remains visible after either no preabsorbtion or preabsorbtion with the corresponding nonspecific peptides. The results indicate that the Spn4.1 protein from third instar larval CNS extracts has an apparent molecular weight of $45 \mathrm{kDa}$.

The data are consistent with the synthesis of Spn4.1 in the CNS. We therefore used immunocytochemistry on wholemount third instar ganglia to localize the Spn4.1 protein. Affinity-purified antibodies either to recombinant whole Spn4.1- $\mathrm{H}_{6}$ (Fig. $3 A, B$ ) or to the C-terminal peptide (Fig. $3 C, D$ ) both labeled a similar set of lateral (Fig. $3 B, D$ ) and dorsomedial neurons (Fig. $3 A, C$ ). The labeled cells resembled the pattern of Spn4-positive cells detected through in situ hybridization of Spn 4 mRNA (Fig. $3 E)$. Double labeling with Spn4.1 and Even skipped antibodies demonstrates that three of the Spn4-positive dorsomedial cells are the motoneurons RP2 and aCC and the interneuron pCC (Fig. $3 F$ ). This result is intriguing given that neuroserpin, the closest vertebrate relative of Spn4.1, also shows neuron-specific expression during development and in adult animals (Osterwalder et al., 1996; Krueger et al., 1997). Besides its expression in the CNS, Spn4 expression was also detected in peripheral tissues, notably the secretory epitracheal Inka cells (Fig. 3G,H). These cells regulate molting behavior through the secretion of ETH (O'Brien and Taghert, 1998; Park et al., 1999). The expression of Spn 4 in Inka cells is intriguing given the molting phenotypes observed after Spn4.1 overexpression (see below).

\section{Spn4.1 is an inhibitory serpin}

Spn4.1 has amino acid sequences at both its hinge region and its primary specificity (P1) site that are typical for serpins that inhibit proteases, specifically those that cleave their substrates at basic amino acid residues (Schechter and Berger, 1967). To test whether Spn4.1 forms complexes with candidate proteases, we expressed and purified Spn4.1- $\mathrm{H}_{6}$ and performed in vitro complex formation experiments with a panel of commercially available serine proteases. Figure $4 A$ shows that $\mathrm{Spn} 4.1-\mathrm{H}_{6}$ forms SDS-stable high molecular weight complexes (Spn4.1* protease complexes) after incubation with trypsin, plasmin, and thrombin, but not with chymotrypsin or elastase. The apparent molecular weights of those complexes equaled the calculated sum of the Spn4.1- $\mathrm{H}_{6}$ and the catalytic subunits of the respective proteases.

We used the three antisera raised to the full-length recombinant Spn4.1, to the protein core, and to the C terminus of the molecule to determine the identity of the higher molecular weight complexes, as well as the serpin fragments that arise after interaction with trypsin (Fig. $4 B$ ). The antiserum against the fulllength recombinant protein (Fig. $4 A$, $B$, left panel) detected the high molecular weight complex (Spn4.1*trypsin complex), fulllength $\mathrm{Spn} 4.1-\mathrm{H}_{6}$, and several cleaved and degradatory products (Spn4.1 core and Spn4 fragments). The identity of these fragments was confirmed by using the affinity-purified antisera raised against a peptide from the protein core (Fig. $4 B$, middle panel), which revealed a pattern similar to one from the fulllength antisera. In contrast, only the full-length $\mathrm{Spn} 4.1-\mathrm{H}_{6}$ was 
$\mathbf{A}$

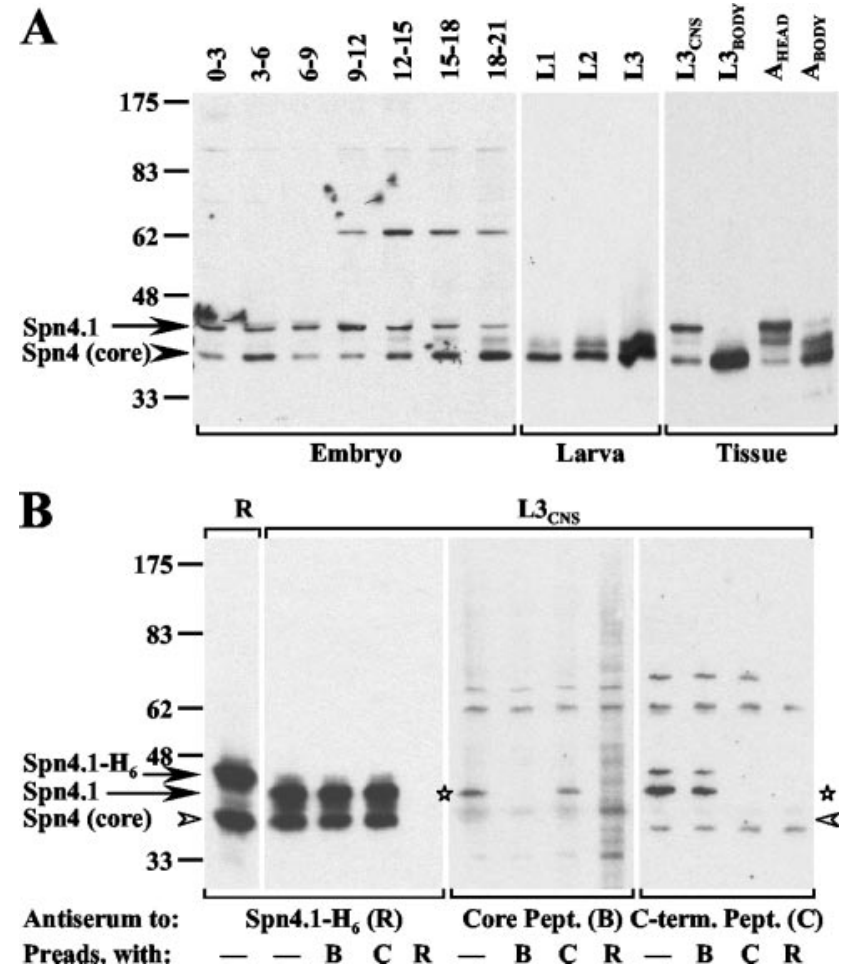

Figure 2. Developmental Western blots of Spn4. A, Western blots of protein extracts from $0-3 \mathrm{hr}$ through $18-21 \mathrm{hr}$ embryos and from the first through third instar larvae (L1-L3) were probed with a guinea pig antiserum to recombinant Spn4.1 protein. The final four lanes show tissue homogenates: third instar larval CNS ( $\mathrm{L}_{\mathrm{CNS}}$; comprising dissected brain hemispheres and ventral ganglia), larval bodies ( $\mathrm{L}_{\mathrm{BODY}}$; comprising the posterior two-thirds of the animal, less the $(N S)$, and adult heads $\left(A_{\text {HEAD }}\right.$ ) and bodies $\left(A_{\text {BODY }}\right)$. The molecular weights expected for full-length Spn $4.1(45 \mathrm{kDa}$ ) and the proteolytically cleaved Spn 4 core ( $40 \mathrm{kDa}$ ) are indicated by arrows. $B$, Specificity controls for the antisera. Protein samples (as marked above the blot): $\mathrm{R}$, partially tryptically processed recombinant $\mathrm{Spn} 4.1-\mathrm{H}_{6} ; \mathrm{L}_{\mathrm{CNS}}$, larval CNS preparations as in $A$. Blots were probed with guinea pig antisera to recombinant $\mathrm{Spn} 4.1-\mathrm{H}_{6}(\mathrm{R})$ and rabbit antisera to the core peptide (B) or to the $\mathrm{C}$-terminal peptide (C). Specificity was tested by preabsorbtion of the antisera with the respective antigens $B, C$, or $R$, or with no peptide $(-)$, as indicated below the figure. Molecular weights are indicated in kilodaltons (left). The molecular weights expected for full-length $\mathrm{Spn} 4.1-\mathrm{H}_{6}(47 \mathrm{kDa})$, the proteolytically cleaved serpin core $(40 \mathrm{kDa})$, and the full-length Spn4.1 (45 kDa) are indicated by arrows. The latter is marked by the stars.

recognized by the antisera against the last $15 \mathrm{C}$-terminal amino acids (Fig. $4 B$, right panel). This is consistent with trypsin cleaving Spn4.1 within the reactive site loop, so that the $\mathrm{C}$ terminus is lost after reductive denaturation in SDS-PAGE buffer, regardless of whether the protease remains associated with the cleaved serpin in a covalent serpin ${ }^{\star}$ trypsin complex, or if the complex disintegrates eventually to release the serpin core.

\section{Spn4.1 inhibits the SPC protease furin in vitro}

Given the intriguing amino acid composition at the reactive site, we hypothesized that a physiological target of Spn4.1 might be a subtilisin-like proprotein convertase. We therefore chose to test whether Spn4.1 can directly interact with the canonical SPC protease furin. In vitro complex formation assays were performed between Spn4.1- $\mathrm{H}_{6}$ and a soluble form of recombinant mammalian furin (Bravo et al., 1994) under conditions of $\mathrm{pH}, \mathrm{Ca}^{2+}$, and temperature compatible with insect SPC activity. Figure $5 \mathrm{~A}$ shows that Spn4.1 readily forms an SDS-stable high molecular weight complex of the expected size (Spn $4^{\star}$ furin complex) at both a 1:10 and a 1:5 molar ratio of furin to Spn4.1- $\mathrm{H}_{6}$. Under these conditions only a small portion of the total serpin is cleaved
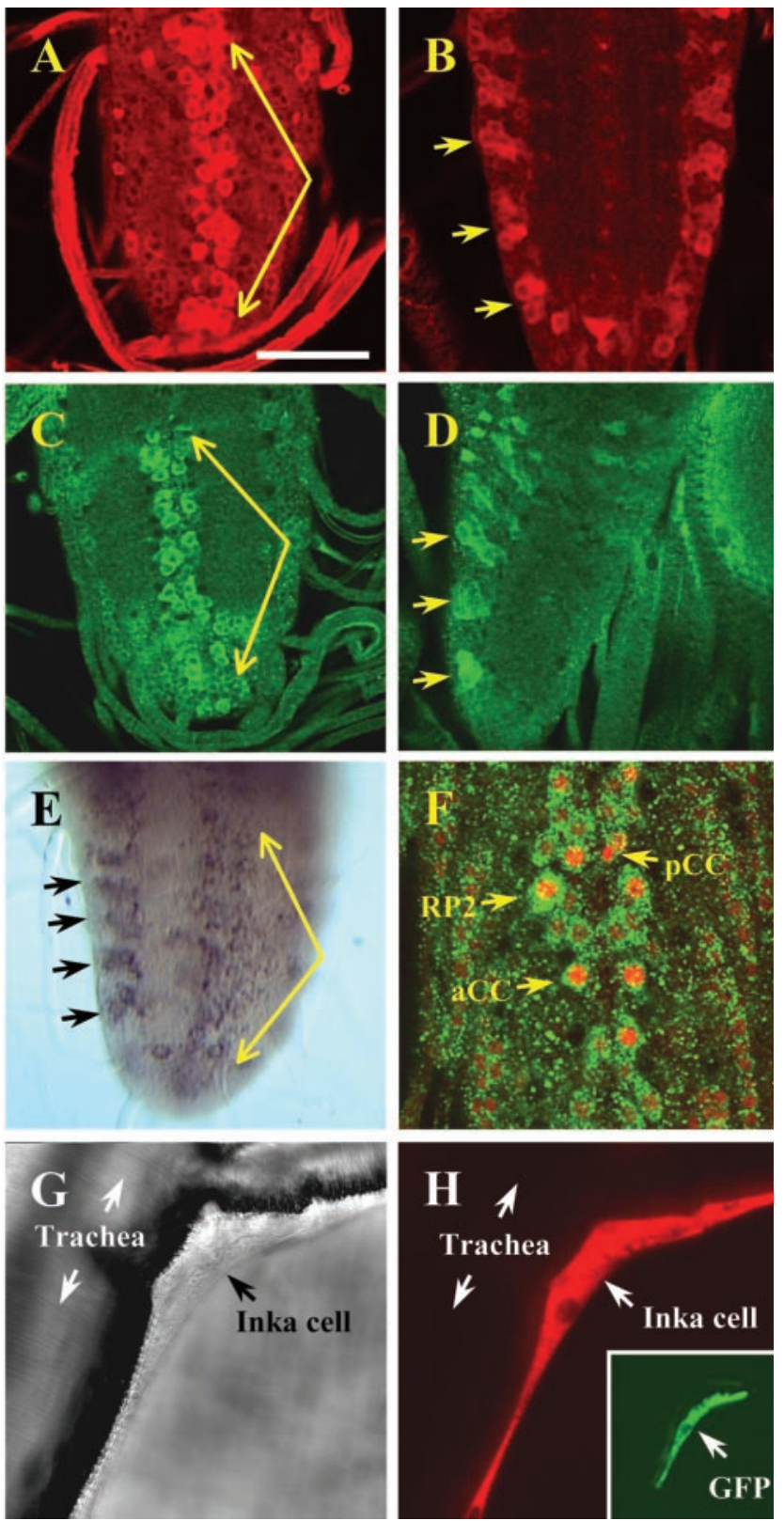

Figure 3. Cellular expression of Spn 4 in third instar larval CNS neurons and epitracheal cells. $A, B, S p n 4$ protein revealed by antiserum against recombinant $S p n 4.1-H_{6} . C, D, S p n 4.1$ protein revealed by antiserum against the $C$-terminal peptide of Spn4.1. The images show both dorsomedial ( $A, C$, long arrows) and lateral ( $B, D$, arrows) cells, the patterning of which is reminiscent of known motoneurons. E, Spn4 mRNA in situ hybridization labels a pattern of lateral (short arrows) and dorsomedial (long arrows) cells similar to the pattern revealed by the two antisera. F, Double labeling of L3 CNS neurons with C-terminal Spn4.1 antiserum (green fluorescence) and anti-Even skipped antibodies (red fluorescence) shows that the motoneurons RP2 and aCC, as well as the interneuron pCC, are Spn4.1 positive (arrows). $G, H$, Tracheal preparations from third instar larvae from the $2 \mathrm{E} 3 \mathrm{G}$ transgenic line that expresses an ETH-GFP fusion protein in epitracheal Inka cells (Park et al., 2002). G, Differential interference contrast image of an Inka cell probed with a polyclonal antiserum against recombinant Spn4.1 (shown in $H$ ). $H$, The Spn4 immunolabeling (red fluorescence) colocalized with the GFP expression of the Inka cell (inset). Scale bars: $A-E, 50 \mu \mathrm{m} ; F, 25 \mu \mathrm{m} ; G, H, 10 \mu \mathrm{m}$.

(Spn4 core). As in the preceding complex formation experiments, the high molecular weight complex is recognized only by antibodies raised against either the entire Spn4.1 protein (Fig. 5A, left panel) or a peptide from the core region of Spn4.1 (Fig. 5A, middle panel), but not by an antiserum specific to the $\mathrm{C}$ terminus 

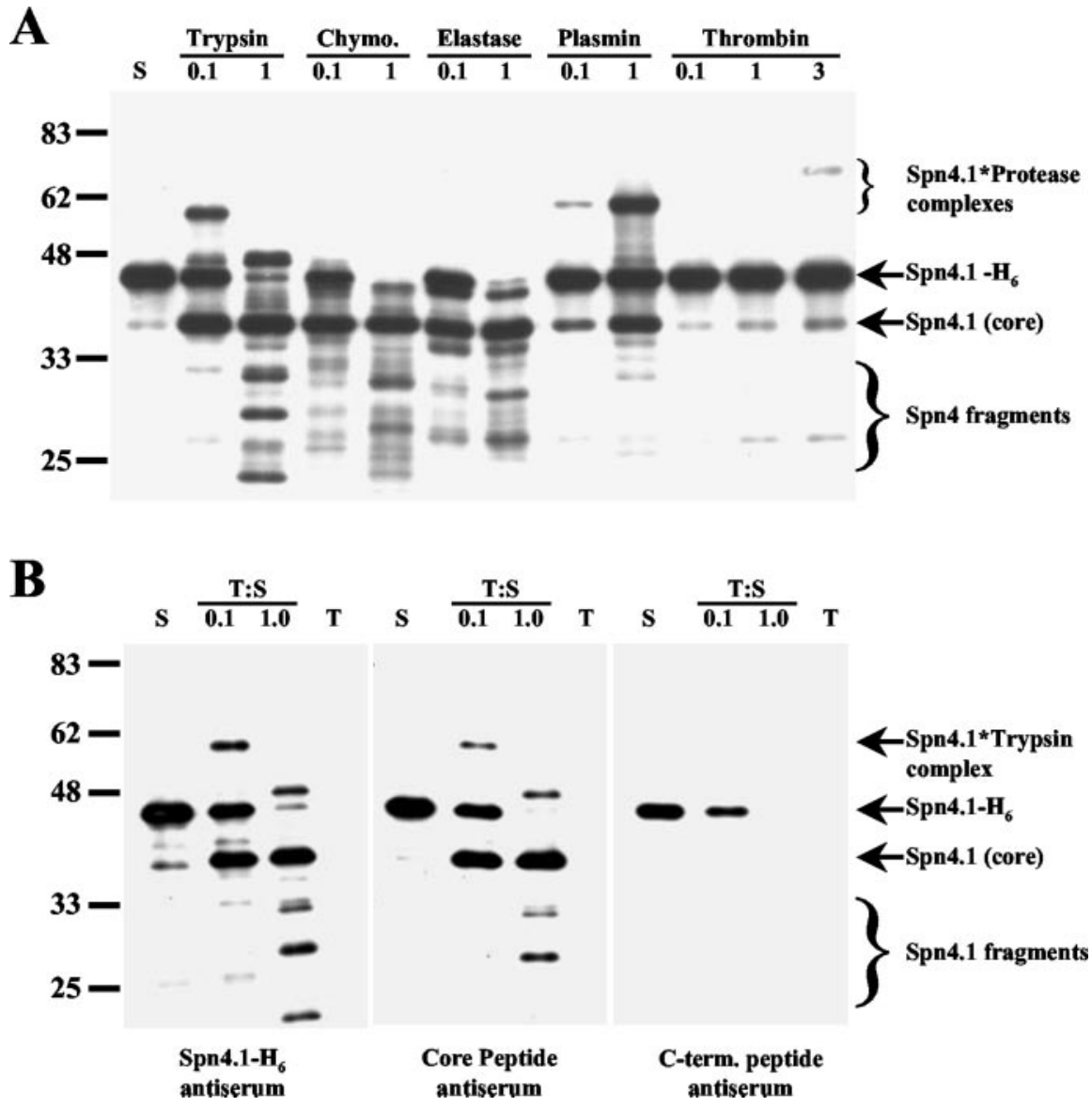

Figure 4. In vitro interaction of Spn4.1 with serine proteases. A, Western blot analysis of Spn4 after in vitro reaction of Spn4.1- $\mathrm{H}_{6}$ with no protease $(S)$; trypsin, chymotrypsin, elastase, and plasmin at either 1:10 or equimolar ratios $(0.1,1)$; and thrombin at 1:10, equimolar, or threefold molar ratio to $\mathrm{Spn}_{4} .1-\mathrm{H}_{6}(0.1,1,3)$. The antiserum against Spn4.1- $\mathrm{H}_{6}$ reveals the full-length Spn4.1- $\mathrm{H}_{6}$, the high molecular weight complexes (Spn4* protease complexes), as well as proteolytically cleaved Spn4 (core) and degraded Spn4 fragments. B, Characterization of Spn4*trypsin complexes using affinity-purified antibodies raised against the full-length recombinant protein (left panel), the protein core (middle panel), or the ( terminus (right panel). The Spn4.1- $\mathrm{H}_{6}$ alone (S); the trypsin:Spn4.1- $\mathrm{H}_{6} \operatorname{mix}(\mathrm{T}: \mathrm{S} ; 0.1,1)$ and trypsin alone (T) were probed. None of the antisera cross-reacted to trypsin ( $\mathrm{T}$ lanes). Antisera raised against either the full-length recombinant $\mathrm{Spn} 4.1-\mathrm{H}_{6}$ or the core peptide recognized a similar pattern, consisting of the Spn4*trypsin complex, the full-length Spn4.1, and cleaved Spn4 (core and fragments). In contrast, antisera against the C-terminal peptide recognized only the uncleaved $\mathrm{Spn} 4.1-\mathrm{H}_{6}$ (right panel).

(Fig. $5 A$, right panel). None of the antisera recognized a high molecular weight band in the absence of furin (Fig. $5 A$, lanes marked "S") or any protein when furin preparations alone were loaded (Fig. $5 A$, lanes marked " $\mathrm{F}$ "). The results indicate that $\mathrm{Spn} 4.1-\mathrm{H}_{6}$ interacts with and forms SDS-stable complexes with furin in the expected, serpin-like manner.

In a second set of experiments, we determined whether the proteolytic activity of furin is inhibited by Spn4.1. We measured residual furin enzymatic activity after preincubation with Spn $4.1-\mathrm{H}_{6}$ and found up to a $65 \%$ reduction of amidolytic activity using an eightfold molar excess of Spn4.1- $\mathrm{H}_{6}$ (Fig. 5B). From an extrapolation of furin activity to zero, we calculated a 11.5-fold molar excess of Spn4.1- $\mathrm{H}_{6}$ to be sufficient to completely inhibit recombinant, soluble human furin. A different experimental regimen was chosen to study the reaction kinetics of Spn4.1- $\mathrm{H}_{6}$ and furin (Fig. 5C). The second order rate constant, $k_{\mathrm{a}}$, for the interaction of $\mathrm{Spn} 4.1-\mathrm{H}_{6}$ with furin was determined under pseudo first-order conditions using the progress curve method (Morrison and Walsh, 1988). By nonlinear regression using Equations 1 and 2 (see Materials and Methods), we calculated a $k_{\mathrm{a}}$ of $2.1 \times 10^{5}$ $\mathrm{M}^{-1} / \mathrm{sec}^{-1}$. These experiments reveal that Spn 4.1 has the bio- chemical hallmarks of an inhibitory serpin: it can form stable complexes with SPCs and inhibit their proteolytic activity.

\section{Overexpression of either Spn4 or neuroserpin leads to larval molting defects}

Having demonstrated the antiproteolytic activity of Spn $4.1-\mathrm{H}_{6}$ in vitro, we wished to find candidates for the in vivo target proteases of Spn4.1. We chose a genetic approach, reasoning that the phenotype resulting from overexpression of Spn4.1 might resemble a LOF phenotype of the cognate protease(s). The bipartite expression system using Gal4 drivers (Brand and Perrimon, 1993) was used to express the transgenes UAS-Spn4.1 and UAS-Spn4.2. Given the structural similarity between Spn4.1 and vertebrate neuroserpin, we also generated UAS-Neus lines. As a control we used UASSpn27A to express the secreted Drosophila serpin 27A (with a basic amino acid at P1) (Fig. 1C) (De Gregorio et al., 2002). Gain-offunction (GOF) phenotypes were generated with the c929-Gal4 driver, which is expressed in virtually all central peptidergic neurons as well as in the epitracheal Inka cells of the periphery (see Fig. 7C) (O'Brien and Taghert, 1998; Hewes et al., 2003).

We observed a significant increase in both larval and pupal lethality when single copies of either Spn4.1 or Neus were expressed using the c929-Gal4 driver (Fig. 6). All Spn4.1 or Neus insertion lines tested showed no apparent defects in either embryonic development or hatching. The first instar larvae exhibited no significant defects in either locomotion or feeding behavior; however, there was a block of developmental progress at a characteristic point in larval ecdysis (molting) for several UAS-Spn4.1 and Neus inserts that resulted in larval death. The strongest effects were observed for the Spn4.1 ${ }^{283}$ allele, which resulted in complete first instar larval lethality (Fig. 6). Other Spn4.1 alleles and all Neus alleles tested showed ecdysis phenotypes at either the second to third instar larval molt or during the pupal stage, where we observed partially collapsed animals within the pupal cases. Similar effects were observed for several independent insertions for the UAS-Neus and the UASSpn4.1 transgenes on different chromosomes. Significantly, expression of the alternatively spliced Spn 4.2 isoform or serpin 27A did not cause molting defects or lethality above control levels. Animals homozygous for UAS-serpin inserts but lacking Gal4 drivers were also fully viable, indicating that lethality was not caused by a transgene position effect or disruption of an endogenous gene. Finally, we noted lethality and molting defects for Spn4.1 and Neus when crossed to the more broadly expressing 24B-Gal4 driver (with the larvae arresting development at the L1 to L2 ecdysis) (Fig. 7F). 24B-Gal4 drives expression in mesodermal tissues as well as in a subset of ectodermal tissues in both the periphery and CNS of larvae (Brand and Perrimon, 1993).

The phenotypes resulting from Spn4.1 or Neus overexpres- 


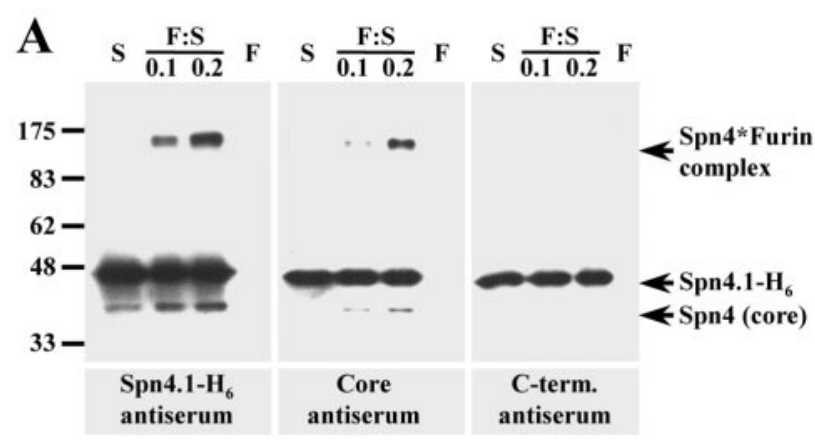

B
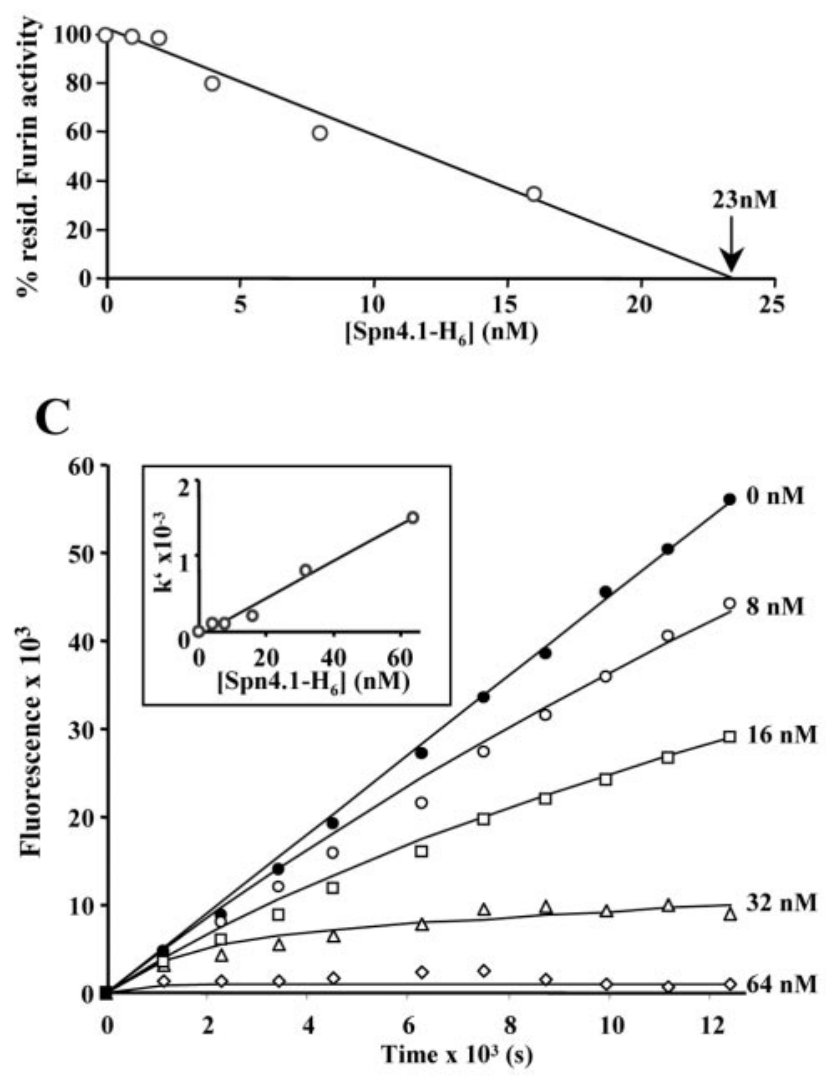

Figure 5. Spn4.1 forms SDS-stable complexes with and inhibits furin/SPC1 in vitro. A, Western blot analysis of Spn4.1 reaction products after incubation of Spn4.1- $\mathrm{H}_{6}$ with recombinant, soluble human furin. Either the $\mathrm{Spn} 4.1-\mathrm{H}_{6}$ alone $(\mathrm{S})$, a furin:Spn4.1- $\mathrm{H}_{6}$ mixture of either 1:10 or 1:5 molar ratio (F:S; $0.1,0.2$ ), or furin alone (F) was probed. Both the full-length recombinant Spn4.1- $\mathrm{H}_{6}$-specific antiserum (left panel) and the core peptide-specific antiserum (middle panel) recognized full-length and cleaved Spn4.1 as well as a $\sim 120 \mathrm{kDa}$ complex between Spn4.1 and furin. The C-terminal peptide-specific antiserum recognized only uncleaved Spn4.1- $\mathrm{H}_{6}$ (right panel). $\mathrm{B}$, Residual amidolytic activity of $2 \mathrm{~nm}$ recombinant furin was tested with the furin-specific fluorogenic substrate pERTKR-MCA after preincubation with progressively higher concentrations of Spn4.1- $\mathrm{H}_{6}$. By extrapolation of residual furin activity, a 11.5-fold molar excess of Spn4.1- $\mathrm{H}_{6}(23 \mathrm{~nm}$; arrow) is anticipated to fully inhibit furin activity under these experimental conditions. C, Kinetic parameters of furin:Spn4.1- $\mathrm{H}_{6}$ interaction were determined under pseudo first-order conditions using the progress curve method. Inhibition of $2 \mathrm{~nm}$ furin at different concentrations of $\mathrm{Spn} 4.1-\mathrm{H}_{6}$ was followed by measuring the product concentration every $1200 \mathrm{sec}$. The first-order rate constants $\left(k^{\prime}\right)$ were calculated for each Spn4.1- $\mathrm{H}_{6}$ concentration by using Equation 1 (the solid lines are a best fit based on a numerical solution to the equation). The association rate constant $\left(k_{\mathrm{a}}\right)$ of $2.1 \times 10^{5} \mathrm{M}^{-1} / \mathrm{sec}^{-1}$ was obtained from the slope of the line showing the dependence of $k^{\prime}$ on the Spn4.1- $\mathrm{H}_{6}$ concentration (inset), corrected with $K_{\mathrm{m}}$ according to Equation 2 (see Materials and Methods).

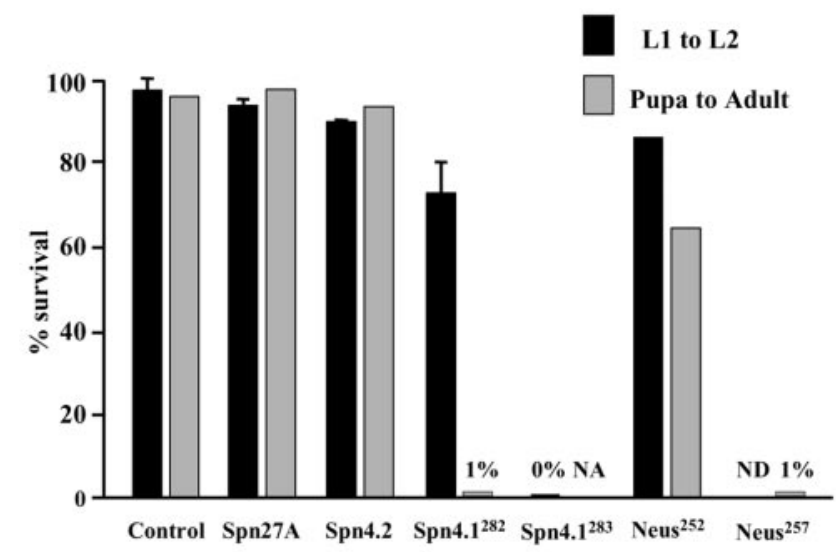

Figure 6. Overexpression of Spn4.1 in a small number of peptidergic cells causes arrest at developmental transitions. The $929-$ Gal4 driver was crossed to UAS-Spn27A, UAS-Spn4.2, UAS-Spn4.1 (UAS-Spn4. $1^{282}$ or UAS-Spn4. ${ }^{283}$ ), or UAS-neuroserpin (UAS-Neus ${ }^{252}$ or UASNeus ${ }^{257}$ ) to generate animals with one copy of the driver and one copy of the UAS construct. Survival rate at developmental transitions from first to second instar larva (black bars) or pupal eclosion (gray bars) is indicated as percentage of the expected number of animals. NA, Not applicable (all animals die at the first to second instar ecdysis); ND, not determined; Control, c929-Gal4 driver alone with no UAS transgene.

sion were caused by the failure to progress through ecdysis. The feeding apparatus of larvae includes sclerotized mouthhooks (MHs) and ventral plates (VPs) with morphology characteristic for each larval instar (Fig. $7 A, B$ ). Normally, the second instar mouth hooks (MHII) and vertical plates (VPII) arise adjacent to the first instar complement (MHI and VPI) and become sclerotized at $24 \mathrm{hr}$ after hatching. This event coincides with the onset of the ecdysis of the first instar larval cuticle and the transition to the second instar; a similar developmental sequence occurs at the second to third instar molt (Park et al., 2002). The period when double mouthhooks and double vertical plates are evident lasts normally for $\sim 1 \mathrm{hr}$ during the molt. Larvae overexpressing either Spn4.1 or Neus were able to proceed to the sclerotized double mouthhooks and double ventral plates stage normally but then remained trapped there for up to $24 \mathrm{hr}$ (Figs. $7 D-F$ ).

The molting phenotype observed for Spn4.1 or Neus overexpression has been reported for mutations of several genes involved in peptide expression, processing, or signaling. These include mutations of the structural gene for the secreted peptide ETH (Park et al., 2002), mutations of peptidylglycine $\alpha$-hydroxylating monooxygenase, the rate-limiting enzyme for C-terminal $\alpha$-amidation of secretory peptides (Jiang et al., 2000), and mutations of the peptide-processing enzyme amontillado (amon), the Drosophila ortholog of the mammalian serine protease PC2 (Siekhaus and Fuller, 1999; Rayburn et al., 2003). The latter is of particular interest because the Spn4.1 GOF apparently phenocopies a serine protease LOF mutation. One interpretation of these GOF experiments is that either Spn 4.1 or Neus inhibits one or more SPCs, resulting in a disruption of the proteolytic processing of the peptides from their precursor proproteins. The expression of Spn4.1 in epitracheal Inka cells (Fig. 3G,H) and the molting phenotypes that occur after overexpression of Spn4.1 with c929-Gal4 raise the possibility that the serpin targets serine protease processing those cells and thus regulates the expression of ETH (Park et al., 2002).

\section{Discussion}

Spn4 is a Drosophila protein that resembles neuroserpin, a vertebrate serine protease inhibitor that is involved in various aspects 

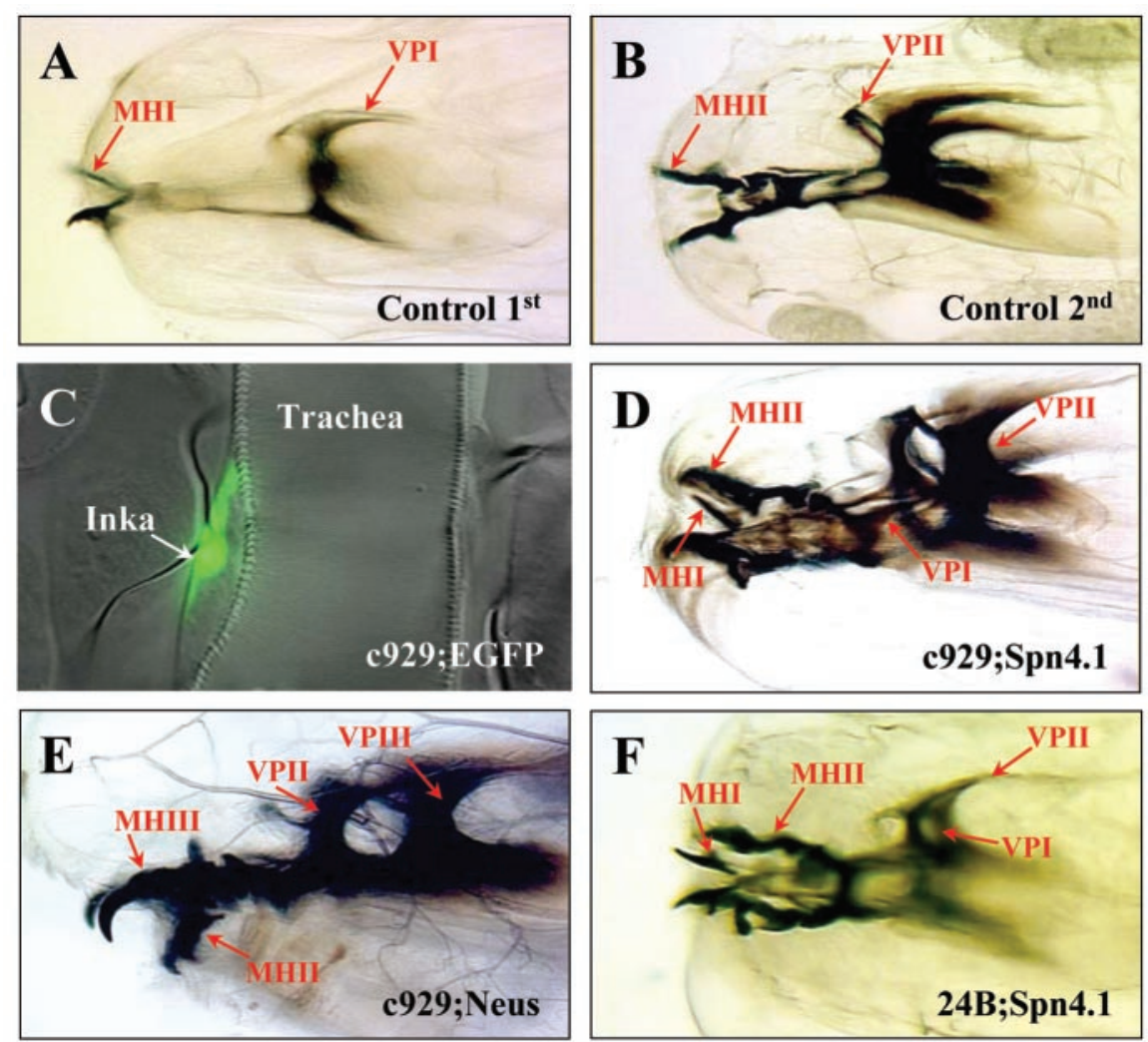

Figure 7. Larval molting defects caused by directed expression of Spn4.1 or Neus using either the c929-Gal4 or 24B-Gal4 drivers. $A$, Larval mouthparts of first instar larvae normally have a single set of morphologically distinct mouthhooks (MH1) and vertical plates (VPI). $B$, Second instar larvae similarly have a single set of mouthhooks (MHII) and vertical plates (VPII). C, The c929-Gal4 line drives expression in central peptidergic neurons (O'Brien and Taghert, 1998) as well as in the epitracheal Inka cells, shown here by EGFP expression. Larvae overexpressing either Spn4.1 (D) or Neus $(E)$ using the $(929-G a l 4$ driver arrest at the double mouthhook (MHI plus MHII) and double vertical plate (VPI plus VPII) stage. F, A similar molting phenotype can also be observed in larvae expressing Spn4.1 under the control of the more broadly expressing 24B-Gal4 driver.

of nervous system plasticity (Hastings et al., 1997; Osterwalder et al., 1998). The Spn4.1 isoform functions as a serine protease inhibitor, covalently binding to several serine proteases in vitro, as well as biochemically inhibiting the SPC furin. We propose that in vivo Spn4.1 inhibits SPCs, enzymes that process peptide precursors. This is supported by the unique combination in Spn4.1 of an ER-retention signal and a target sequence for SPCs in the reactive site loop. In vivo Spn4 is expressed by multiple CNS neurons as well as the peripheral peptidergic epitracheal "Inka" cells (Fig. $3 G, H$ ), in which pro-ETH is thought to be processed by SPCs (Rayburn et al., 2003). Overexpression of Spn4.1 results in developmental phenotypes that resemble mutations of the gene encoding ETH and mimics the hypomorphic mutations of the Drosophila SPC gene amontillado. This suggests that overexpression of Spn4.1 in vivo inhibits one or more SPCs that normally activate ETH and other peptides involved in molting behavior.

\section{Spn4 is a unique Drosophila serpin with significant similarity to vertebrate neuroserpin}

Although 35 Drosophila sequences are annotated as serpin-like (Adams et al., 2000; Rubin et al., 2000), fewer than half have the necessary features to be considered functional serine protease inhibitors. These features include the size of the molecule, an appropriate serpin signature in the $\mathrm{C}$-terminal region, and a highly conserved region at the reactive site hinge (Hopkins and Stone, 1995).

Beyond meeting these criteria, Spn4 has at least four additional features that set it apart from the other putative serpins. First, the Spn4 gene has an intron-exon structure that could generate multiple transcripts by mutually exclusive usage of the last exon (Fig. 1A). Mutually exclusive splicing to generate different reactive sites from a single gene has been reported for Caenorhabditis elegans and Drosophila (Kruger et al., 2002) and for the serpin-1 gene of Manduca sexta, in which alternative pre-mRNA splicing generates distinct serpin proteins with distinct reactive site loops that could potentially regulate multiple serine proteases (Jiang et al., 1994). Although similar transcript splicing has not yet been reported in mammals, we note that the location and "phase" of the intron located between exon 3 and exon 4 of Spn 4 is conserved in mammalian neuroserpin (Fig. 1C) (Berger et al., 1998).

Second, the reactive site of the Spn4.1 isoform contains four basic residues at positions P3-P1' (according to standard nomenclature) (Schechter and Berger, 1967) (Fig. 1C), which is unique among the naturally occurring serpins. Although P1 is the primary determinant of the target protease specificity, neighboring residues are involved in an initial interaction with serine proteases (Huber and Carrell, 1989; Bode et al., 1992). The proteases inhibited by Spn4.1 are likely specific for substrates with tandem arrays of basic amino acids.

Third, Spn4.1 has a C-terminal extension unique among the annotated Drosophila serpins but closely resembling the C-terminal region of neuroserpin (Osterwalder et al., 1996; Krueger et al., 1997; Schrimpf et al., 1997; Hill et al., 2000). Although the function of the $\mathrm{C}$ terminus of neuroserpin is not known, the Spn4.1 C terminus perfectly matches the $\mathrm{K} / \mathrm{H}-\mathrm{D}-\mathrm{E}-\mathrm{L}$ consensus for the ER retention signal for soluble proteins (Pelham, 1990), suggesting that this isoform functions in the secretory pathway. If the $\mathrm{C}$ terminus plays a role in intracellular trafficking of Spn4.1, then the various isoforms of Spn4 could have distinct target specificities and subcellular localizations. Finally, Spn4.1 protein is expressed in larval neurons and in the adult head, indicating a potential role in nervous system development and function. The similarities between Spn4.1 and neuroserpin indicate that the Drosophila and vertebrate genes are structurally and functionally related, despite an overall sequence identity of only $\sim 30 \%$.

\section{Spn4.1 is an inhibitory serpin and targets prohormone convertases in vitro}

The primary structure suggests that Spn4.1 codes for an inhibitory serpin. To test this we generated a recombinant, biochemically active Spn $4.1-\mathrm{H}_{6}$ that lacks the first 32 amino acid residues, including the presumed signal peptide for secretion, and has a C-terminal 6xHis tag. Using Spn4.1- $\mathrm{H}_{6}$, we demonstrated that Spn4.1 interacts with several chymotrypsin-like serine proteases, forming high molecular weight, SDS-stable complexes in a serpin-like manner (Fig. 4). Consistent with the basic amino acid residues at $\mathrm{P} 1$, these interactions were observed only with serine proteases with basic substrate specificity, such as trypsin, plas- 
min, and thrombin, whereas $\mathrm{Spn} 4.1-\mathrm{H}_{6}$ merely served as a cleavage substrate for chymotrypsin and elastase.

A possible function of Spn 4.1 was suggested by the interaction of Spn4.1- $\mathrm{H}_{6}$ with the SPC furin. Inhibitory interactions with furin have been reported for naturally occurring as well as bioengineered serpin proteins, indicating that serpins can form SDSstable complexes with SPCs (Dahlen et al., 1998; Jean et al., 1998; Tsuji et al., 2002). Significantly, the Spn4.1 reactive site sequence is a perfect match for furin/SPC1 and probably other members of the SPC family (Seidah and Chretien, 1999). In vitro, the reaction of Spn4.1- $\mathrm{H}_{6}$ with recombinant, soluble human furin led to a covalent complex (Fig. 5A). The amidolytic activity of furin could be reduced by up to $65 \%$ with $\mathrm{Spn} 4.1-\mathrm{H}_{6}$ (Fig. $5 B$ ), with a calculated second order rate constant $k_{\mathrm{a}}$ of $2.1 \times 10^{5} \mathrm{M}^{-1} / \mathrm{sec}^{-1}$. These in vitro experiments are consistent with a model in which SPC proteases serve as in vivo targets of Spn4.1.

\section{Spn4.1 and intracellular protein processing}

A feature of Spn4.1 is its C-terminal ER-retention signal (Pelham, 1990). Given the serpin-like interaction of furin and Spn4.1- $\mathrm{H}_{6}$ in vitro, we were interested in the phenotypes resulting from the directed expression of Spn4.1 in secretory cells. This was done by driving Spn4.1 using the Gal4/UAS system in vivo. The observed molting defects in larvae overexpressing Spn4.1 match those reported for amon (PC2) mutants (Siekhaus and Fuller, 1999; Rayburn et al., 2003) as well as for the peptide factor ETH (Park et al., 2002). We hypothesized that overexpressed Spn4.1 inhibits the SPC that normally processes ETH or other peptides involved in the molting process.

Using the narrowly expressed c929-Gal4 driver line, we demonstrated that restricted expression of Spn4.1 in both central peptidergic neurons and epitracheal Inka cells is sufficient to induce severe larval molting defects (Figs. 6, 7). Although it is not known whether the Amontillado serine protease is the SPC that processes $\mathrm{ETH}$, the striking resemblance of the LOF phenotypes for eth and amon and the GOF phenotype for Spn4.1 make this enzyme a reasonable candidate for the physiological activator of ETH and the target of Spn4.1 in Inka cells. We note that Spn4.1 overexpression could equally disrupt the activation of other peptidergic signals involved in ecdysis (Mesce and Fahrbach, 2002). Additional experiments will be needed to test the interaction of ETH, Amontillado, and Spn4.1 on a molecular, a cellular, and a genetic level.

Driving either Spn4.1 or Neus with the broadly expressed 24B-Gal4 driver also arrested development at the double mouthhook and ventral plate stage (Fig. $7 F$ ). In addition to its expression in mesodermally derived tissues (Brand and Perrimon, 1993), the 24B-Gal4 driver drives expression in a subset of peripheral ectodermal tissues, including all larval tracheal cells (but not in the third instar epitracheal Inka cells) (H. Keshishian and Y. Kim, unpublished observations). The 24B-Gal4 line also drives expression in the CNS in a subset of unidentified midline cells (Brand and Perrimon, 1993), as well as strongly in the dorsal neurohemal organs, which are the secretory organs for CNSderived neuropeptides and hormones (Allan et al., 2003; Marques et al., 2003). The molting defects caused by 24B-Gal4driven expression in these tissues may result from the disrupted processing and/or hemolymph secretion of one or more peptides critical for normal ecdysis.

Interestingly, overexpression of vertebrate neuroserpin produced molting defects similar to those seen with Spn4.1. Neuroserpin targets the serine proteases tissue plasminogen activator and urokinase both in vitro and in vivo (Osterwalder et al., 1998;
Cinelli et al., 2001). Neuroserpin is also expressed in a number of endocrine cells (Hill et al., 2000) and interacts with SPC3 in vitro (L. Coates, R. Hill, and N. Birch, unpublished observation). As we propose for Spn4.1, one of the physiological roles of neuroserpin may be to regulate peptide processing. Moreover, given their specificity, neuroserpin or Spn4.1 could serve as useful experimental tools for controlling peptide expression, using inducible gene expression methods to target these proteins to specific cells (Osterwalder et al., 2001; Roman et al., 2001).

In conclusion, we examined Spn4.1 overexpression in vivo and observed molting defects strikingly similar to those seen for the LOF of the SPC2 protease Amontillado or the LOF of the ETH peptide. We have shown that Spn4.1 inhibits in vitro the SPC furin, a close relative of amontillado/SPC2, in a serpin-like manner. Collectively, these data support the hypothesis that Spn4.1 and possibly vertebrate neuroserpin belong to a class of serpins with intracellular function involved in the regulation of prohormone processing (Hook et al., 1994; Hwang et al., 1999, 2000). This sheds new light on the role of serpins in general, and of Spn4.1 (and most likely neuroserpin) in particular, and points to a new level of regulation of proteolytic processing.

\section{References}

Adams MD, Celniker SE, Holt RA, Evans CA, Gocayne JD, Amanatides PG, Scherer SE, Li PW, Hoskins RA, Galle RF, George RA, Lewis SE, Richards S, Ashburner M, Henderson SN, Sutton GG, Wortman JR, Yandell MD, Zhang Q, Chen LX, et al. (2000) The genome sequence of Drosophila melanogaster. Science 287:2185-2195.

Allan DW, St. Pierre SE, Miguel-Aliaga I, Thor S (2003) Specification of neuropeptide cell identity by the integration of retrograde BMP signaling and a combinatorial transcription factor code. Cell 113:73-86.

Barr PJ (1991) Mammalian subtilisins: the long-sought dibasic processing endoproteases. Cell 66:1-3.

Berger P, Kozlov SV, Krueger SR, Sonderegger P (1998) Structure of the mouse gene for the serine protease inhibitor neuroserpin (PI12). Gene 214:25-33.

Bode W, Gomis-Ruth FX, Huber R, Zwilling R, Stocker W (1992) Structure of astacin and implications for activation of astacins and zinc-ligation of collagenases. Nature 358:164-167.

Brand AH, Perrimon N (1993) Targeted gene expression as a means of altering cell fates and generating dominant phenotypes. Development 118:401-415.

Bravo DA, Gleason JB, Sanchez RI, Roth RA, Fuller RS (1994) Accurate and efficient cleavage of the human insulin proreceptor by the human proprotein-processing protease furin. Characterization and kinetic parameters using the purified, secreted soluble protease expressed by a recombinant baculovirus. J Biol Chem 269:25830-25837.

Cinelli P, Madani R, Tsuzuki N, Vallet P, Arras M, Zhao CN, Osterwalder T, Rulicke T, Sonderegger P (2001) Neuroserpin, a neuroprotective factor in focal ischemic stroke. Mol Cell Neurosci 18:443-457.

Dahlen JR, Jean F, Thomas G, Foster DC, Kisiel W (1998) Inhibition of soluble recombinant furin by human proteinase inhibitor 8 . J Biol Chem 273:1851-1854.

De Gregorio E, Han SJ, Lee WJ, Baek MJ, Osaki T, Kawabata S, Lee BL, Iwanaga S, Lamaitre B, Brey PT (2002) An immune-responsive Serpin regulates the melanization cascade in Drosophila. Dev Cell 3:581-592.

Dufour EK, Denault JB, Hopkins PC, Leduc R (1998) Serpin-like properties of alpha1-antitrypsin Portland towards furin convertase. FEBS Lett 426: 41-46.

Fell B, Smith AM, Hill RM, Parmar PK, Coates LC, Mezey E, Birch NP (2002) Characterisation of two serine protease inhibitors expressed in the pituitary gland. Arch Physiol Biochem 110:26-33.

Green C, Levashina E, McKimmie C, Dafforn T, Reichhart JM, Gubb D (2000) The necrotic gene in Drosophila corresponds to one of a cluster of three serpin transcripts mapping at 43A1.2. Genetics 156:1117-1127.

Halfon MS, Gisselbrecht S, Lu J, Estrada B, Keshishian H, Michelson AM (2002) New fluorescent protein reporters for use with the Drosophila Gal4 expression system and for vital detection of balancer chromosomes. Genesis 34:135-138. 
Han J, Zhang H, Min G, Kemler D, Hashimoto C (2000) A novel Drosophila serpin that inhibits serine proteases. FEBS Lett 468:194-198.

Hastings GA, Coleman TA, Haudenschild CC, Stefansson S, Smith EP, Barthlow R, Cherry S, Sandkvist M, Lawrence DA (1997) Neuroserpin, a brain-associated inhibitor of tissue plasminogen activator is localized primarily in neurons. Implications for the regulation of motor learning and neuronal survival. J Biol Chem 272:33062-33067.

Henikoff S, Henikoff JG (1994) Protein family classification based on searching a database of blocks. Genomics 19:97-107.

Hewes RS, Park D, Gauthier SA, Schaefer AM, Taghert PH (2003) The bHLH protein Dimmed controls neuroendocrine cell differentiation in Drosophila. Development 130:1771-1781.

Hill RM, Parmar PK, Coates LC, Mezey E, Pearson JF, Birch NP (2000) Neuroserpin is expressed in the pituitary and adrenal glands and induces the extension of neurite-like processes in AtT-20 cells. Biochem J 345:595-601.

Hook VY, Azaryan AV, Hwang SR, Tezapsidis N (1994) Proteases and the emerging role of protease inhibitors in prohormone processing. FASEB J $8: 1269-1278$

Hopkins PC, Stone SR (1995) The contribution of the conserved hinge region residues of alpha1-antitrypsin to its reaction with elastase. Biochemistry 34:15872-15879.

Huber R, Carrell RW (1989) Implications of the three-dimensional structure of alpha 1-antitrypsin for structure and function of serpins. Biochemistry 28:8951-8966.

Huntington JA, Carrell RW (2001) The serpins: nature's molecular mousetraps. Sci Prog 84:125-136.

Hwang SR, Steineckert B, Yasothornsrikul S, Sei CA, Toneff T, Rattan J, Hook VY (1999) Molecular cloning of endopin 1, a novel serpin localized to neurosecretory vesicles of chromaffin cells. Inhibition of basic residuecleaving proteases by endopin 1. J Biol Chem 274:34164-34173.

Hwang SR, Steineckert B, Hook VY (2000) Expression and mutagenesis of the novel serpin endopin 2 demonstrates a requirement for cysteine-374 for dithiothreitol-sensitive inhibition of elastase. Biochemistry 39:8944-8952.

Hwang SR, Steineckert B, Toneff T, Bundey R, Logvinova AV, Goldsmith P, Hook VY (2002) The novel serpin endopin 2 demonstrates cross-class inhibition of papain and elastase: localization of endopin 2 to regulated secretory vesicles of neuroendocrine chromaffin cells. Biochemistry 41 : 10397-10405.

Jean F, Boudreault A, Basak A, Seidah NG, Lazure C (1995) Fluorescent peptidyl substrates as an aid in studying the substrate specificity of human prohormone convertase $\mathrm{PC} 1$ and human furin and designing a potent irreversible inhibitor. J Biol Chem 270:19225-19231.

Jean F, Stella K, Thomas L, Liu G, Xiang Y, Reason AJ, Thomas G (1998) alpha1-Antitrypsin Portland, a bioengineered serpin highly selective for furin: application as an antipathogenic agent. Proc Natl Acad Sci USA 95:7293-7298.

Jiang H, Wang Y, Kanost MR (1994) Mutually exclusive exon use and reactive center diversity in insect serpins. J Biol Chem 269:55-58.

Jiang N, Kolhekar AS, Jacobs PS, Mains RE, Eipper BA, Taghert PH (2000) PHM is required for normal developmental transitions and for biosynthesis of secretory peptides in Drosophila. Dev Biol 226:118-136.

Keshishian H, Chiba A, Chang TN, Halfon MS, Harkins EW, Jarecki J, Wang L, Anderson M, Cash S, Halpern ME, Johansen J (1993) Cellular mechanisms governing synaptic development in Drosophila melanogaster. J Neurobiol 24:757-787.

Krueger SR, Ghisu GP, Cinelli P, Gschwend TP, Osterwalder T, Wolfer DP, Sonderegger P (1997) Expression of neuroserpin, an inhibitor of tissue plasminogen activator, in the developing and adult nervous system of the mouse. J Neurosci 17:8984-8996.

Kruger O, Ladewig J, Koster K, Ragg H (2002) Widespread occurrence of serpin genes with multiple reactive centre-containing exon cassettes in insects and nematodes. Gene 293:97-105.

Laemmli UK (1970) Cleavage of structural proteins during the assembly of the head of bacteriophage T4. Nature 227:680-685.

Marques G, Haerry TE, Crotty ML, Xue M, Zhang B, O'Connor MB (2003) Retrograde Gbb signaling through the Bmp type 2 receptor wishful thinking regulates systemic FMRFa expression in Drosophila. Development 130:5457-5470.

Mesce KA, Fahrbach SE (2002) Integration of endocrine signals that regulate insect ecdysis. Front Neuroendocrinol 23:179-199.

Morrison JF, Walsh CT (1988) The behavior and significance of slow- binding enzyme inhibitors. Adv Enzymol Relat Areas Mol Biol 61:201-301.

O’Brien MA, Taghert PH (1998) A peritracheal neuropeptide system in insects: release of myomodulin-like peptides at ecdysis. J Exp Biol 201:193-209.

Osterwalder T, Contartese J, Stoeckli ET, Kuhn TB, Sonderegger P (1996) Neuroserpin, an axonally secreted serine protease inhibitor. EMBO J 15:2944-2953.

Osterwalder T, Cinelli P, Baici A, Pennella A, Krueger SR, Schrimpf SP, Meins M, Sonderegger P (1998) The axonally secreted serine proteinase inhibitor, neuroserpin, inhibits plasminogen activators and plasmin but not thrombin. J Biol Chem 273:2312-2321.

Osterwalder T, Yoon KS, White BH, Keshishian H (2001) A conditional tissue-specific transgene expression system using inducible GAL4. Proc Natl Acad Sci USA 98:12596-12601.

Park Y, Zitnan D, Gill SS, Adams ME (1999) Molecular cloning and biological activity of ecdysis-triggering hormones in Drosophila melanogaster. FEBS Lett 463:133-138.

Park Y, Filippov V, Gill SS, Adams ME (2002) Deletion of the ecdysistriggering hormone gene leads to lethal ecdysis deficiency. Development 129:493-503.

Pelham HR (1990) The retention signal for soluble proteins of the endoplasmic reticulum. Trends Biochem Sci 15:483-486.

Rayburn LYM, Gooding HC, Choksi SP, Maloney DM, Kidd AR, Siekhaus DE, Bender M (2003) amontillado, the Drosophila homolog of the prohormone processing protease $\mathrm{PC} 2$, is required during embryogenesis and early larval development. Genetics 163:227-237.

Roman G, Endo K, Zong L, Davis RL (2001) P[Switch], a system for spatial and temporal control of gene expression in Drosophila melanogaster. Proc Natl Acad Sci USA 98:12602-12607.

Rubin GM, Spradling AC (1982) Genetic transformation of Drosophila with transposable element vectors. Science 218:348-353.

Rubin GM, Yandell MD, Wortman JR, Gabor Miklos GL, Nelson CR, Hariharan IK, Fortini ME, Li PW, Apweiler R, Fleischmann W, Cherry JM, Henikoff S, Skupski MP, Misra S, Ashburner M, Birney E, Boguski MS, Brody T, Brokstein P, Celniker SE, et al. (2000) Comparative genomics of the eukaryotes. Science 287:2204-2215.

Schechter I, Berger A (1967) On the size of the active site in proteases. I. Papain. Biochem Biophys Res Commun 27:157-162.

Schrimpf SP, Bleiker AJ, Brecevic L, Kozlov SV, Berger P, Osterwalder T, Krueger SR, Schinzel A, Sonderegger P (1997) Human neuroserpin (PI12): cDNA cloning and chromosomal localization to 3q26. Genomics 40:55-62.

Seidah NG, Chretien M (1999) Proprotein and prohormone convertases: a family of subtilases generating diverse bioactive polypeptides. Brain Res 848:45-62.

Siekhaus DE, Fuller RS (1999) A role for amontillado, the Drosophila homolog of the neuropeptide precursor processing protease PC2, in triggering hatching behavior. J Neurosci 19:6942-6954.

Sorsa V (1988) Chromosome maps of Drosophila. Boca Raton, FL: CRC.

Steiner DF (1998) The proprotein convertases. Curr Opin Chem Biol 2:31-39.

Tautz D, Pfeifle C (1989) A non-radioactive in situ hybridization method for the localization of specific RNAs in Drosophila embryos reveals translational control of the segmentation gene hunchback. Chromosoma 98:81-85.

Thacker C, Rose AM (2000) A look at the Caenorhabditis elegans Kex2/ Subtilisin-like proprotein convertase family. BioEssays 22:545-553.

Towbin H, Staehelin T, Gordon J (1979) Electrophoretic transfer of proteins from polyacrylamide gels to nitrocellulose sheets: procedure and some applications. Proc Natl Acad Sci USA 76:4350-4354.

Tsuji A, Hashimoto E, Ikoma T, Taniguchi T, Mori K, Nagahama M, Matsuda Y (1999) Inactivation of proprotein convertase, PACE4, by alpha1antitrypsin Portland (alpha1-PDX), a blocker of proteolytic activation of bone morphogenetic protein during embryogenesis: evidence that PACE4 is able to form an SDS-stable acyl intermediate with alpha1-PDX. J Biochem (Tokyo) 126:591-603.

Tsuji A, Ikoma T, Hashimoto E, Matsuda Y (2002) Development of selectivity of alpha1-antitrypsin variant by mutagenesis in its reactive site loop against proprotein convertase. A crucial role of the $\mathrm{P} 4$ arginine in PACE4 inhibition. Protein Eng 15:123-130. 